\title{
Mentorship: service, education, progress. The 2015 CNS Presidential Address
}

\author{
Nathan R. Selden, MD, PhD \\ Department of Neurological Surgery, School of Medicine, Oregon Health \& Science University, Portland, Oregon
}

The theme of the 65th Annual Meeting of the Congress of Neurological Surgeons and the title of this presidential address focus on mentorship as a valuable service owed to the profession of neurological surgery by its members, a crucial tool for the education of new neurosurgeons, and a fundamental contributor to the progress of the specialty. The author explores the origin of the term "mentor" in Homeric tradition and the impact of mentorship on the historical legacy of neurological surgery. He outlines the role mentorship played in his own professional development, as well as the changing face of mentorship today due to increasing numbers of women in neurosurgery.

Many surgeons perceive modern educational approaches as threats to the tradition of personal mentorship in medicine. The author argues that intentional educational methods, such as the Society of Neurological Surgeons (SNS) "matrix" curriculum, the Accreditation Council for Graduate Medical Education "milestones," and the SNS "boot camp" courses, each focus, enhance, and empower, but do not replace, personal mentorship. The author further describes the important role of mentorship in the definition, growth, and health of the specialty of neurological surgery and in the personal wellbeing and fulfillment of its practitioners.

http://thejns.org/doi/abs/10.3171/2016.2.JNS152606

KEY WORDS presidential address; mentorship; education; curriculum; boot camp courses; residency; gender; profession

A life is not important, except in the impact it has on other lives.

$$
\text { - Jackie Robinson }{ }^{15}
$$

Baseball legend Jackie Robinson had exceptional talent, extraordinary determination, and a deep reservoir of personal goodwill. He broke the color barrier in American professional sports, went on to mentor a generation of talented young players, and raised the hopes of millions more who dreamed of similar success.

More than any other field in medicine, mentorship defines the specialty of neurological surgery, and forms the core of our own professional identity. I was trained by Dr. Julian T. (“Buz") Hoff (Fig. 1). Buz's homespun modesty, personal warmth, and powerful intellect stay with me as I make rounds in the hospital, stand at the scrub sink, or talk with nurses in the break room. His mentorship appeared in simple, unplanned, and profound ways. On the first day of junior residency, Buz spent 2 hours teaching me how to perform a lumbar discectomy. He used a skin marker to draw diagrams of each step onto the surgical drapes. Sometimes, in the hallway after conference, he would ask, "What are you writing these days?", and would then respond to my answer with insightful questions and encouragement. Once, after losing one of his favorite patients to their disease, Buz put his hand on my shoulder and said quietly, "Well, Nate, we did our best." And when we could help a patient, Buz's excitement and pride in our team were palpable. Watching Buz, we learned how to be neurosurgeons.

Our Oregon Health \& Science University (OHSU) residents have never met Dr. Hoff, but I've shared enough Hoff anecdotes, aphorisms, and surgical pearls with them that they feel they know him. And, in a way, they do. Each of us carries this special bond; with our "chief," with our favorite senior resident, or with the faculty mentor who took us under his wing and helped us make the transition from student to neurosurgeon.

The value of mentorship is clear, but its origins are obscure. The term mentor originated almost 3000 years ago from a very minor character in Homer's The Odyssey (2.225-56). The ancient Greek king and warrior Odysseus left on a legendary journey, entrusting his household and his son, Telemachus, to a close friend and advisor, Mentor. Mentor's charge was to embody reason and wisdom,

ABBREVIATIONS AANS $=$ American Association of Neurological Surgeons; ABNS $=$ American Board of Neurological Surgery; ACGME $=$ Accreditation Council for Graduate Medical Education; CNS = Congress of Neurological Surgeons; OHSU = Oregon Health \& Science University; SNS = Society of Neurological Surgeons.

SUBMITTED November 11, 2015. ACCEPTED February 4, 2016.

INCLUDE WHEN CITING Published online May 6, 2016; DOI: 10.3171/2016.2.JNS152606. 


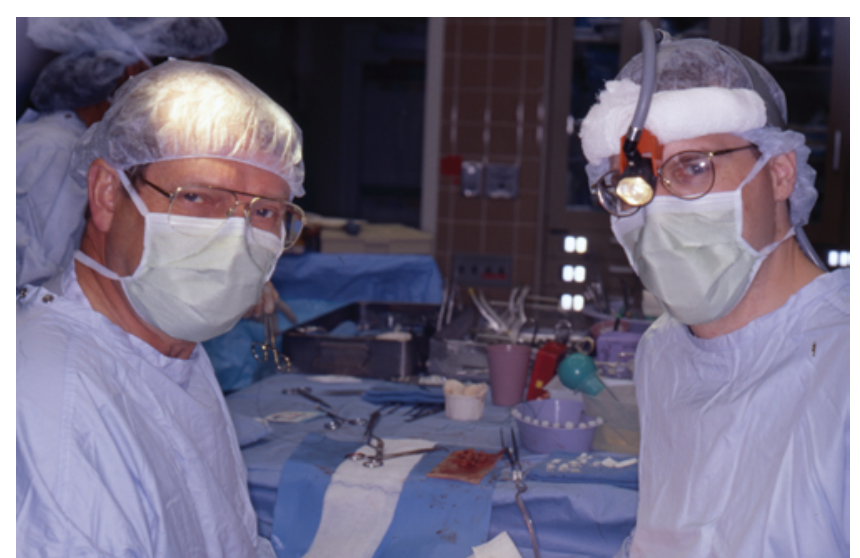

FIG. 1. The author with his mentor, Dr. Julian "Buz" Hoff, operating at the University of Michigan Medical Center in 1999. Author's personal collection. Figure is available in color online only.

to protect the household, and to help raise Telemachus. In the ancient Greek, Mentor signifies "a man who thinks."

Our own foundational mentorship history is just as powerful. Harvey Cushing left a larger imprint on neurosurgery and mentored a more extensive school than anyone else. Cushing's most famous and accomplished protégé was Walter Dandy. In fact, Cushing's mentorship of Dandy is one of the most fascinating relationships in medicine. When Dandy worked with Cushing in the Hunterian lab at Johns Hopkins, he invalidated some of Cushing's original findings on sympathectomy and glucose metabolism. ${ }^{5}$ Cushing's mentorship of Dandy was fractured, and never recovered. He soon left Johns Hopkins for Boston, and left Dandy behind.

Dandy emerged as a vigorous innovator, a daring and accomplished surgeon, and a powerful mentor in his own right. He pioneered ventricular endoscopy and contrast imaging, choroid plexus coagulation, and aneurysm clipping. ${ }^{5}$ At the same time, he maintained lifelong warm relationships with his friends and trainees. ${ }^{11} \mathrm{He}$ was also an engaged and compassionate family man. In short, Dandy is an outstanding role model for us all.

In Walter Dandy's era, a mentor was paired, literally, with a surgical apprentice. Even 20 years ago when I began training, most residents worked as "serial apprentices," with a new rotation and a new mentor about every 6 months. Sustained personal interaction with a single mentor was the core of most surgical education. In the last 20 years, however, the world has changed radically, threatening these personal ties between mentor and trainee.

Subspecialty expertise has exploded. Technology is evolving at a breathtaking pace. Hospitals, health care systems, and insurers have created a relative value unit treadmill that demands ever-increasing efficiency, prolonged work hours, and almost inhuman focus on productivity. At the same time, the government has created a sea of regulations and electronic checkboxes that distract from our patients, take us away from our colleagues, and rob us of precious time. The traditional paradigm of mentor and protégé is at risk. Is mentorship even relevant to surgical education today? The answer is a resounding "yes."
The data are clear. Mentorship is crucial in attracting the best medical students to surgery. A specific surgical mentor influenced the career decision of most general surgery residents..$^{10,12,16}$ Mentors are the pivotal influence on choice of specialty and practice setting. ${ }^{18,27}$ We also know that expert performance develops only after years of deliberate practice under the guidance of a gifted mentor or coach. ${ }^{4}$

But most importantly, mentorship is the best way for us to promote our own values and define our own worth. Mentorship is also the only way to develop a truly shared vision of the future and help others realize their role in achieving it. In short, effective personal mentorship is more important than ever.

The most effective mentors are strong professional role models and recognized experts, who also serve as leaders in their institutions. They dedicate time and effort to their mentorship role. They communicate well and set clear expectations. Most notably, they avoid seizing credit for mentored work. ${ }^{3}$ Effective mentorship involves as much listening as speaking, as much guidance as direction, and as much encouragement as persuasion.

Sadly, our personal differences can interfere with good mentorship., ${ }^{9} 17$ Age, background, and gender can create serious barriers. But I know from personal experience this need not be the case. I'm a pediatric neurosurgeon today because a tenacious and gifted faculty member, Dr. Karin Muraszko, inspired me to follow in her path (Fig. 2). Utterly committed to pediatric neurosurgery, Karin was a terrific mentor and role model. One Friday evening, 6 hours into a very difficult case, a pediatric resident came into our operating room to show us the MRI of a baby with a newly diagnosed brainstem tumor and severe hydrocephalus. Karin glanced up at the clock and quietly gave instructions to prepare the child for surgery. She then nodded at me to continue and coached me as I finished the dissection for our current patient. I'll never forget Karin's determination, resilience, and focus on patients. As a mentor she was demanding and required excellence. She also set clear expectations, communicated directly when I fell short, and offered specific encouragement when I progressed.

The concept of women as mentors is far from new. The "man who thinks" from The Odyssey actually failed. Thieves overran Odysseus' household and suitors pursued his wife. A "woman who thinks" was the one who finally saved the day. In the ancient story, Athena, the goddess of wisdom and of war, disguised herself as Mentor, reestablished order, and served as "an experienced and trusted advisor" to Telemachus (The Odyssey, 2.268-3.240, 4.654-655, 22.206-249, 24.446-548). A woman, Athena, is in fact the eponymous founder of mentorship.

No doubt, the challenge, complexity, and lasting impact of neurosurgery demand uniformly high standards when we choose residents and when we train them. Put simply, not everyone can become a neurosurgeon. However, to paraphrase the Walt Disney movie, Ratatouille, "a good neurosurgeon can come from anywhere." This light-hearted parable about a humble animal who becomes a worldclass chef reminds us of a common barrier to professional diversity and successful mentorship, which is our own im- 


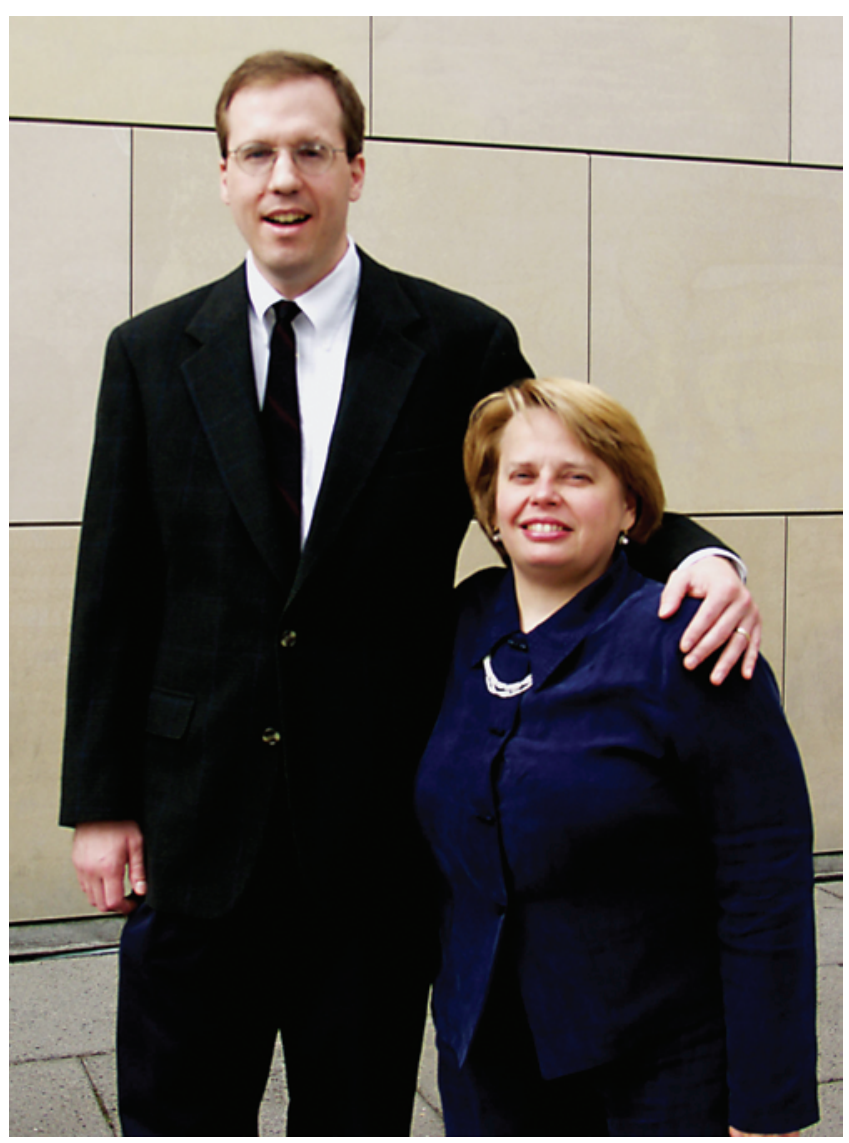

FIG. 2. The author with his mentor, Dr. Karin Muraszko, on the occasion of her visiting professorship at the Department of Neurological Surgery, OHSU, in 2001. Author's personal collection. Figure is available in color online only.

age of a mentor's and a protégé's appearance, background, and gender. ${ }^{19}$

When the 2015 class of neurosurgery residents began work at OHSU, female trainees represented a majority of the program for the first time (Fig. 3). These 9 women are also the largest number ever training simultaneously at a single Accreditation Council for Graduate Medical Education (ACGME) neurosurgery residency. Other department and program leaders have asked me how we attracted women to OHSU and what they can do to achieve the same results.

The answer is simple: we focused on matching the very best medical students. Female applicants were a significant part of that focus. We created a welcoming environment for all candidates at our interview weekends, including women. We also instituted a generous family leave policy, equally supportive of both women and men starting families. Most importantly, we worked hard to actively mentor the female residents already in our program. The first women in the program shared their experiences. New residents were drawn to an environment where everyone is treated fairly and equally. ${ }^{19}$

Women entering neurosurgery residency now match their proportion in the applicant pool: about $20 \%$. But that proportion has stalled. We don't need compromises, and we don't need quotas. But underutilizing the talent present in half the population is no longer acceptable for a specialty, like ours, in need of the very best raw material for the future.

Neurosurgeons should actively mentor every medical student talented enough to join the next generation. We know that students choose their mentors, not the other way around. The very best students will not approach us for mentorship unless we're exemplary role models. And they won't stay unless we respond to those priceless initial opportunities with openness, warmth, and attention. ${ }^{19}$

$[\mathrm{P}]$ eople will forget what you said, people will forget what you did, but people will never forget how you made them feel.

- Maya Angelou ${ }^{14}$

Life in neurosurgery is tough and that poses challenges to effective mentorship. What does our neurosurgical lifestyle look like to today's medical students? Are we positioned to inspire the next generation of neurosurgeons?

We can and must demonstrate unwavering dedication to patients' welfare and expect it of trainees. But we should also organize our practices, and our lives, to serve as the best mentors possible at work, at home, and in our community. We should mindfully schedule small gaps into our busy routine. We should pause, reflect, and spend time with those around us. We should remember that email is there 24 hours a day, but our students, our younger colleagues, and our spouses are there only for part of it. We should avoid the overwhelming temptation to focus on the technical and forget the human aspects of our jobs and of our lives. To secure the future of our profession, we should inspire the best men and women to pursue a career in neurological surgery and set an example that they can follow with enthusiasm and pride.

Mentorship is one key to success, but it is no longer enough. Even the best aspects of our traditional apprenticeship model of training cannot keep up with the exploding knowledge base and technological complexity of neurosurgery. Only 20 years ago, I trained to localize brain tumors using a pencil, a ruler, and a printed scan. In practice, I have used a 3D computer navigation system. Recently, we have begun using a 3-Tesla, 10-ton intraoperative magnetic resonance scanner. Twenty years ago, pediatric neurosurgery was still an emerging subspecialty. Today, my younger colleagues sub-subspecialize in pediatric skull base surgery or neuroendoscopy. Neurosurgical education, by comparison, has fallen dangerously behind. Incredibly, only 3 years ago US neurosurgery residency directors first endorsed a universal national curriculum. Until 2 years ago, we had no systematic method of measuring clinically relevant educational outcomes.

Simply exposing residents to an adequate learning environment for 7 years no longer guarantees success, safety, or quality. Without using surgical navigation, one operation is at risk. But without modern, effective, and outcomes-driven education, thousands of operations may be at risk every time we train a new neurosurgeon. Also at risk are our reputation, our ability to communicate and inspire, and our credibility in every operating room, classroom, and hospital boardroom in the country. 


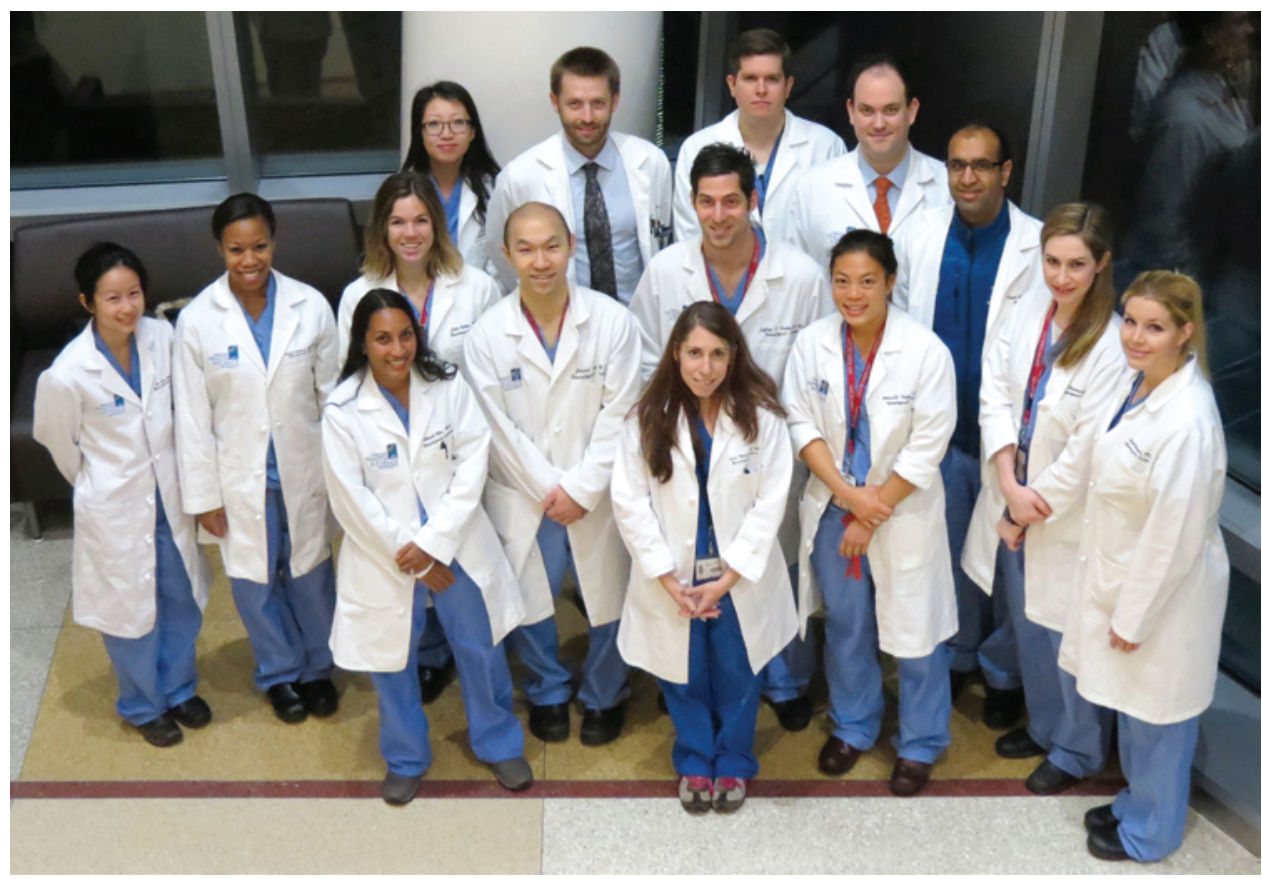

FIG. 3. Neurological surgery residents at OHSU in November 2015: Jacob Bagley, MD, Kelly Bridges, MD, Erik Brown, MD, PhD, Carli Bullis, MD, Jo Ling Goh, MD, Kunal Gupta, MBBChir, PhD, Frances Hardaway, MD, Katie L. Krause, MD, PhD, Yimo Lin, MD, Jesse Liu, MD, Paul McMahon, MD, Priscilla Pang, MD, MS, Abigail Rao, MD, Jeffrey Raskin, MD, MS, Lauren Simpson, MD, MPH, and Tristan M. Stani, MD (not pictured). With permission from the Department of Neurological Surgery at OHSU School of Medicine. Figure is available in color online only.

$[\mathrm{I}] \mathrm{t}$ is through good education that all the good in the world arises.

\section{- Immanuel Kant ${ }^{7}$}

The philosopher Immanuel Kant did not mean that education is good simply because it preserves our current state of knowledge. He meant that good education gradually creates new knowledge and progress. A former Harvard University president put it more bluntly:

If you think education is expensive, try ignorance.

$$
\text { - Derek Bok }{ }^{25}
$$

Facing these challenges, neurosurgery has moved from an era of apprenticeship to an era of intentional education, and has emerged as a leader among the 24 major medical and surgical specialties in advancing real and effective outcomes-based education reform. Current efforts include 3 major components: a validated national curriculum, robust educational outcome goals, and shared national resources. Each of these 3 components is aimed at focusing, enhancing, and empowering-but not replacing-the personal mentorship of every trainee.

The initial effort involved the creation in 2012 of a national curriculum for neurosurgery validated by US residency directors in the Society of Neurological Surgeons (SNS). Conceived by the Congress of Neurological Surgeons (CNS) Honored Guest, and my own faculty mentor for the last 15 years, Dr. Kim Burchiel, this "matrix" curriculum covers the technical aspects of neurosurgery as well as general competencies such as leadership, communications, safety, and continuous improvement.
An effective curriculum focuses residents and faculty mentors on the core knowledge necessary to succeed. But too many curricula end up as lists, sitting on a shelf and gathering dust. To avoid this, CNS leaders have worked tirelessly in partnership with the SNS and the American Association of Neurological Surgeons (AANS) to launch the Neurosurgery Portal project. The Portal will serve as a dynamic and interactive classroom that will define and teach the core of our specialty. Residents will access surgical videos, lectures, and short quizzes, and also generate objective progress reports. When it launches in early 2016, the Portal will be a powerful and innovative resource for online teaching.

I am always ready to learn, although I do not always like being taught, ...

$$
\text { - Winston Churchill }{ }^{2}
$$

Personal mentorship transforms rote teaching, like the Portal, into real learning. But mentorship is also chaotic and disorderly. In the modern hospital, mentorship is spread across teams of not just doctors, but also physicians' assistants, nurses, and technicians. Feedback to trainees is largely informal and sporadic. There is real risk that individual residents will randomly miss out on crucial guidance needed for their ultimate independence, safety, and success.

This problem has spurred a major new direction in graduate medical education. In 2012, the ACGME, which oversees all US medical and surgical training, mandated use of defined educational goals, or "milestones," for every resident in every specialty. ${ }^{13}$ 


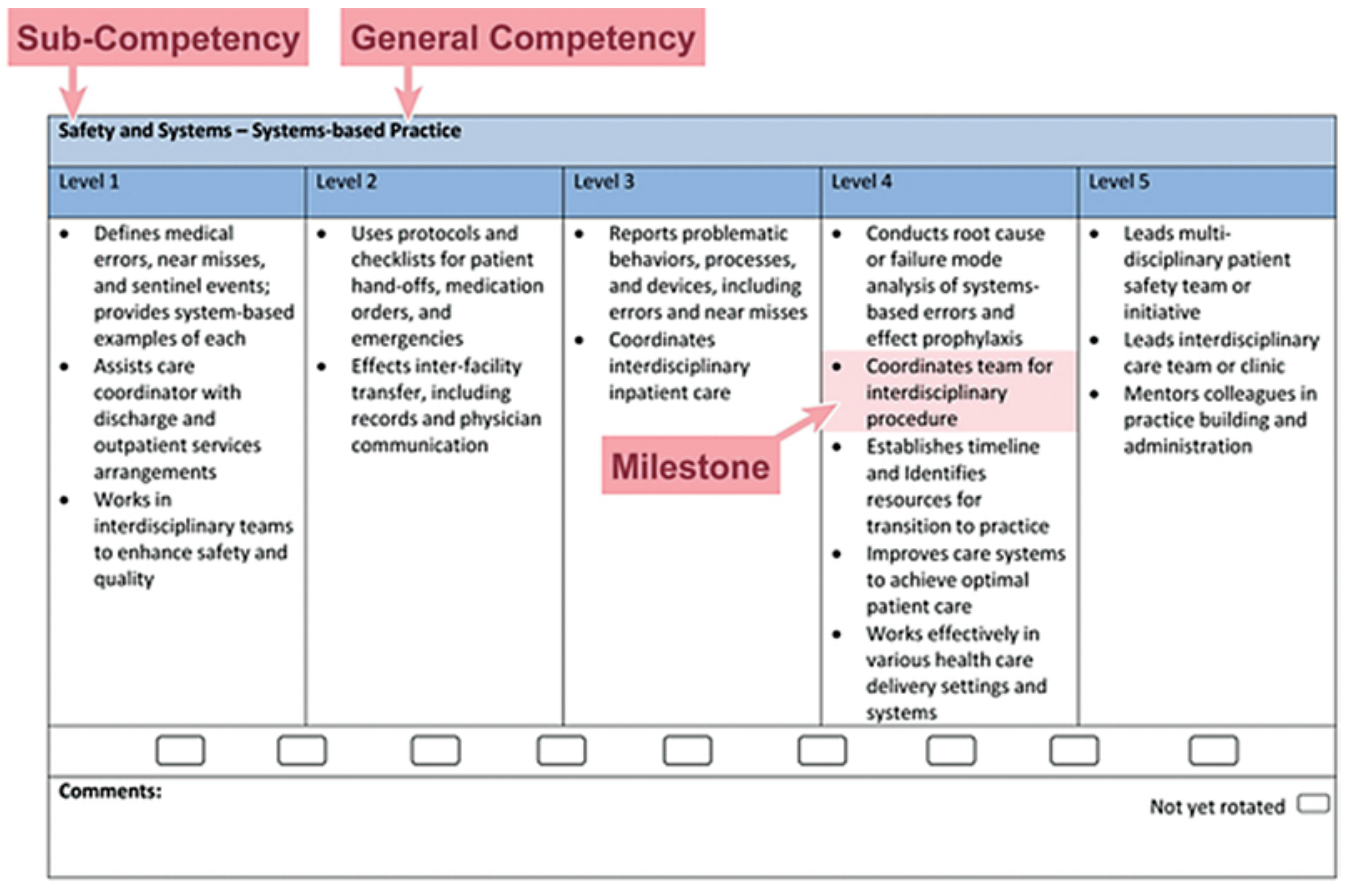

FIG. 4. Chart showing neurological surgery milestones for systems-based practice competency (safety and systems subcompetency), as published in Selden et al. ${ }^{20}$ Reproduced with permission from the ACGME and ABNS. Figure is available in color online only.

With little guidance, and no precedents to follow, neurosurgery and 6 other specialties agreed to lead this second intentional education effort. ${ }^{26}$ In 2013 we published and implemented the Neurological Surgery Milestones, covering 24 domains in 8 sub-subspecialties and the general competencies (Fig. 4). ${ }^{20}$ The milestones are objective individual markers of progress and competence, such as safely placing a ventricular drain, obtaining informed consent, or completing a quality improvement project.

The milestones do not replace mentorship but they do help mentors identify problems early and find solutions. As program director, I sit with the residents, look over their milestone data, and talk with each of them about potential problems or deficits. The milestones provide transparency and reflect consensus. They spark honest conversation, help identify a plan of action, and track success. Residents who do well can do better. We also find the ones who really cannot succeed, and redirect them sooner and more fairly. Most importantly, we help those with the potential for true success who are at risk for failure. At OHSU, we've made a real difference in the progress of multiple residents in just the first 2 years.

The third intentional education effort has focused on providing shared national resources to support core learning. For example, skills training, testing, and simulation are crucial to assure basic competency at the beginning of residency. They're also complex, time-consuming, and expensive. To assist training programs in using these tools, the SNS partnered with the CNS to initiate a national system of "boot camp" courses for every new neurosurgery resident in the country. ${ }^{22,23}$

The boot camps introduce key surgical and procedural skills, such as closing the dura or placing a lumbar drain. They use simple, inexpensive, model-based simulators with intensive faculty mentorship (Fig. 5). ${ }^{24}$ Using mentored simulation, errors become sources of knowledge and experience, rather than risk and injury. ${ }^{8}$ Both faculty and residents concentrate on learning, and develop trust. During one of the first boot camps, a senior faculty member watched a new intern using the perforator drill to make a simulated bur hole. The drill plunged. "When I was a resident," he said, "that would have been a patient."

The boot camps improve knowledge and skills and they enhance safety. ${ }^{21}$ They also enrich the professional fabric of neurosurgery by contributing to a web of common experience that binds neurosurgeons together throughout our careers: the interview trail, the boot camps and now also junior resident courses, the "Research and Update in Neuroscience for Neurosurgeons" course, the written and oral board examinations, and participation in our professional organizations. "The best part of the boot camps," said one resident, "was the camaraderie between interns and faculty." Faculty members from around the country line up to serve at the boot camps. Just a 2-day break from a hectic clinical service, concentrating full-time on mentorship, is precious, not just for the residents, but also for us.

The CNS is proud to partner closely with our colleagues in the SNS, the ACGME, the American Board of Neurological Surgery (ABNS), and the AANS to enhance the progress of education in our specialty. To succeed in a challenging economy, despite an avalanche of regulations, all of our organizations must and are working more closely and effectively together.

Great education empowers, focuses, and enriches, but 


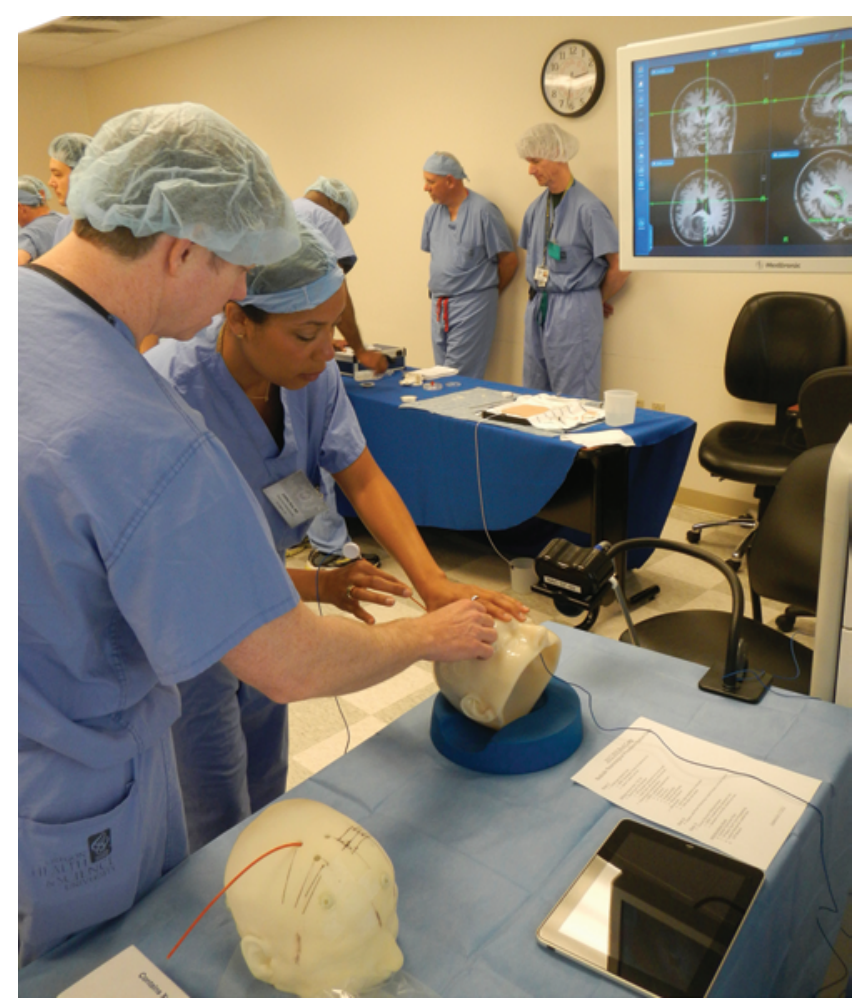

FIG. 5. Mentored simulation for ventriculostomy placement at the SNS Western Region Boot Camp Course, OHSU, July 2012. Author's personal collection. Figure is available in color online only.

never replaces, personal mentorship. Education assures a base of systematic knowledge. It communicates the protégé's strengths and weaknesses to the mentor. It provides the right setting and circumstance for successful mentorship to take place. In turn, mentors motivate students to learn, teach them resilience, and inspire a passion for success.

Since its foundation, the CNS has provided a place for innovative education in a welcoming community of colleagues and mentors. During the Second World War, dozens of young neurosurgeons, with little formal preparation, trained in the crucible of wartime hospitals. Returning home, they were excluded from established neurosurgical societies. They lacked acceptance, education, and mentorship. Banding together in a new society, these returnees mentored one another. That society, today, is the CNS. ${ }^{1} \mathrm{We}$ are proud of this history of inclusiveness and its impact on the vitality of our profession.

We now face another watershed moment. In 2014, the ACGME reached a landmark agreement to create for the first time a single system of postgraduate medical and surgical training for the entire US (https://www.acgme. org/acgmeweb/tabid/445/GraduateMedicalEducation/ SingleGMEAccreditationSystem.aspx). By the end of this decade, there will no longer be separate medical and osteopathic residencies, but rather a single system of ACGME-accredited residencies for all qualified trainees from either allopathic or osteopathic medical schools. Every residency program must now meet ACGME criteria for excellence. Not all osteopathic programs will survive. But those that do will meet the highest standards with shared osteopathic and allopathic faculty.

The CNS has again followed the principles of mentorship and inclusiveness that marked its founding in the aftermath of the Second World War. Any resident in an ACGME-accredited neurosurgery program, whether a medical or osteopathic physician, is automatically a member of the CNS. The Congress also welcomes to full, active membership in its shared community all accredited osteopathic neurosurgeons who wish to contribute to the CNS' educational mission and the high practice standards of its members.

Welcoming these colleagues to the Congress is about putting patients who need neurosurgical care first, and about making sure a highly qualified neurosurgeon is at the bedside of every American suffering from a stroke, trauma, or spinal cord compression. All future neurosurgeons will determine the direction and value of our specialty, and today they need us. We must never surrender and never delegate our most important duty as neurosurgeons: to mentor those around us.

Everyone wants to be mentored but there is no detailed playbook for mentorship. Mentorship is about the protégé; their hopes, their dreams, and their specific needs. Mentorship is its own reward. Most importantly, mentorship requires a profound faith that our most important task in work, in family, and in life is to help those who come after us achieve greater success and greater accomplishment than our own. Everything else flows from that belief.

So I encourage you to take the time to host a student who wants to shadow you in clinic. Someday, they may join and enrich our profession. Accept leadership in your operating room, committee room, or boardroom. Your presence will promote the values and ideals of our specialty. Volunteer for the CNS and our other professional organizations. Your work will ensure the health of our profession and help us determine our own future, by leading rather than following other specialties. Do what neurosurgeons do best: take responsibility and make a greater impact than one could fairly expect of us.

Hippocratic tradition tells us, above all else, to put the patient first, and to selflessly share our skill and knowledge with the next generation of healers (http://www. medicinenet.com/script/main/art.asp?articlekey=20909). Since the foundation of medicine, mentorship has been our duty.

So thank you for everything you do to fulfill this Hippocratic ideal. Thank you for encouraging a student to pursue a life in neurosurgery. Thank you for sharing your experiences and skill with your fellow neurosurgeons, for teaching a nurse how to scrub for a craniotomy, and for helping a husband cope with his wife's illness. Thank you for waking up in the night, for leaving the family dinner early, and for your sacrifice to be at the bedside of every patient who needs you.

\section{Acknowledgments}

I gratefully acknowledge Dr. Nigel Nicholson for expertise regarding Homer's The Odyssey, Mr. Andy Rekito for assistance with graphics and illustrations, Dr. Shirley McCartney for assis- 
tance with manuscript preparation, and Drs. Karen Selden, Anthony Asher, Alan Scarrow, Stephen Kalkanis, Ms. Heidi Waldo, and Mr. Gregory Willard for critical reading of early drafts of the address.

\section{References}

1. Barrow DL, Hadley MN: Fifty years of the congress of neurological surgeons: foundations, objectives, and legacies. Neurosurgery 47:261-267, 2000

2. Churchill W: Debate on the Address, 1952, Vol 507 cc7134. (http://hansard.millbanksystems.com/commons/1952/ nov/04/debate-on-the-address\#S5CV0507P0_19521104_ HOC_74) [Accessed March 10, 2016]

3. Entezami P, Franzblau LE, Chung KC: Mentorship in surgical training: a systematic review. Hand (NY) 7:30-36, 2012

4. Ericsson KA, Prietula MJ, Cokely ET: The making of an expert. Harv Bus Rev 85:114-121, 193, 2007

5. Flamm ES: New observations on the Dandy-Cushing controversy. Neurosurgery 35:737-740, 1994

6. Heubeck A, West S, Hainsworth JB, Hoekstra A, Russo J: A Commentary on Homer's Odyssey. Oxford: Oxford University Press, 1988

7. Kant I: [Education.] Königsberg, Germany: Friedrich Theodor Rink, 1803 (Ger)

8. King A, Holder MG Jr, Ahmed RA: Errors as allies: error management training in health professions education. BMJ Qual Saf 22:516-519, 2013

9. Levinson W, Kaufman K, Clark B, Tolle SW: Mentors and role models for women in academic medicine. West J Med 154:423-426, 1991

10. Lukish J, Cruess D: Personal satisfaction and mentorship are critical factors for today's resident surgeons to seek surgical training. Am Surg 71:971-976, 2005

11. Marmaduke MED: Walter Dandy: The Personal Side of a Premier Neurosurgeon, ed 2. Philadelphia: Wolters Kluwer, 2016

12. Osborn EH: Factors influencing students' choices of primary care or other specialties. Acad Med 68:572-574, 1993

13. Philibert I, Nasca TJ: The next accreditation system: stakeholder expectations and dialogue with the community. J Grad Med Educ 4:276-278, 2012

14. Poulson I: Rise. Sydney: Macmillan, 2008, p 162

15. Robinson J, Duckett A: I Never Had It Made: An Autobiography of Jackie Robinson. New York: HarperCollins, 1972

16. Rubeck RF, Donnelly MB, Jarecky RM, Murphy-Spencer AE, Harrell PL, Schwartz RW: Demographic, educational, and psychosocial factors influencing the choices of primary care and academic medical careers. Acad Med 70:318-320, 1995

17. Sambunjak D, Straus SE, Marusic A: A systematic review of qualitative research on the meaning and characteristics of mentoring in academic medicine. J Gen Intern Med 25:7278,2010
18. Sanfey H, Hollands C, Gantt NL: Strategies for building an effective mentoring relationship. Am J Surg 206:714-718, 2013

19. Selden NR: President's message. CNSQ 16:2, 2015

20. Selden NR, Abosch A, Byrne RW, Harbaugh RE, Krauss WE, Mapstone TB, et al: Neurological surgery milestones. J Grad Med Educ 5 (1 Suppl 1):24-35, 2013

21. Selden NR, Anderson VC, McCartney S, Origitano TC, Burchiel KJ, Barbaro NM: Society of Neurological Surgeons boot camp courses: knowledge retention and relevance of hands-on learning after 6 months of postgraduate year 1 training. J Neurosurg 119:796-802, 2013

22. Selden NR, Barbaro N, Origitano TC, Burchiel KJ: Fundamental skills for entering neurosurgery residents: report of a Pacific region "boot camp" pilot course, 2009. Neurosurgery 68:759-764, 2011

23. Selden NR, Origitano TC, Burchiel KJ, Getch CC, Anderson VC, McCartney S, et al: A national fundamentals curriculum for neurosurgery PGY1 residents: the 2010 Society of Neurological Surgeons boot camp courses. Neurosurgery 70:971-981, 2012

24. Selden NR, Origitano TC, Hadjipanayis C, Byrne R: Modelbased simulation for early neurosurgical learners. Neurosurgery 73 (Suppl 1):15-24, 2013

25. Shapiro FR: The Yale Book of Quotations. New Haven: Yale University Press, 2006

26. Swing SR, Beeson MS, Carraccio C, Coburn M, Iobst W, Selden NR, et al: Educational milestone development in the first 7 specialties to enter the next accreditation system. J Grad Med Educ 5:98-106, 2013

27. Thakur A, Fedorka P, Ko C, Buchmiller-Crair TL, Atkinson JB, Fonkalsrud EW: Impact of mentor guidance in surgical career selection. J Pediatr Surg 36:1802-1804, 2001

\section{Disclosures}

The author reports no conflict of interest.

\section{Supplemental Information \\ Previous Presentations}

This article was presented on September 28, 2015, at a plenary session of the 65th Annual Meeting of the CNS in New Orleans, Louisiana. An earlier version of the section on gender in residency training appeared in the Presidential Message, CNS Quarterly, Fall issue, 2015.

\section{Correspondence}

Nathan R. Selden, Department of Neurological Surgery, Oregon Health \& Science University, 3303 SW Bond Ave., CH8N, Portland, OR 97239. email: seldenn@ohsu.edu. 